MUZIKOLOŠKI ZBORNIK - MUSICOLOGICAL ANNUAL XL

UDK 78.03(4-014)

Oskár Elschek

Institut für Musikwissenschaft, Slowakische Akademie der Wissenschaften, Bratislava

Muzikološki inštitut, Slovaška akademija znanosti, Bratislava

\title{
Mitteleuropas Beitrag zur Stilentwicklung und Geschichte der europäischen Musik
}

\author{
Prispevek Srednje Evrope k slogovnemu \\ razvoju in zgodovini evropske glasbe
}

ZUSAMMENFASSUNG

Mitteleuropa ist entwicklungsgeschichtlich, ethnisch und multikulturell eine offene Region, die kulturgeographisch schwer abgrenzbar ist. Dies ist aus der mehr als 1500jährigen Entwicklung ersichtlich, die entgegen allen dynamischen Veränderungen eine innere Stabilität aufweist. Diese ist Gegenstand einer immensen Anzahl von kulturgeschichtlichen und musikwissenschaftlichen Veröffentlichungen, die wegen der aktuellen Bedeutung Mitteleuropas sich eines besonderen Interesses erfreuen. Die europäische Musik besitzt keine regional homogene Entwicklungsgeschichte, denn die europäische Musik formte sich im Raum und Zeit differeziert - in einer Art Zentrenwanderung. Von Südosteuropa nach Süd- und Südwesteuropa, nach den westlichen Regionen und Westeuropa, wo sich die Gattungen, die bestimmenden Musiker, Kompositionstechniken und die Musikkulturen verlagerten. Mitteleuropa war die Reflexion dieser, vom Mittelalter an, der Scheide des West-Östlichen konfessionellen Konfliktes wurde es immer stärker in diese europäische Vorzugsentwicklung eingebunden. Vom weltlichen einstimmigen Lied zur Mehrstimmigkeit. Mit dem entscheidenden Beitrag zum Kirchenlied bekam Mitteleuropa eine immer wichtigere Stellung in der europäischen Entwicklung, insbesondere zwischen dem 18. und 20. Jahrhundert. Es überlagerten sich regionale, nationale, universale und individuelle Stilbereiche und Mittele-
POVZETEK

Srednja Evropa je razvojnozgodovinsko, etnično in multikulturno odprta regija, ki jo je kulturnogeografsko težko razmejiti. To je razvidno iz več kot 1500 letnega razvoja, ki v nasprotju z vsemi dinamičnimi spremembami izkazuje notranjo stabilnost. Slednja je predmet velikega števila kulturnozgodovinskih in muzikoloških objav, ki se zaradi aktualnega pomena Srednje Evrope kažejo kot posebno zanimive. Evropska glasba nima regionalno homogene razvojne zgodovine, saj se je evropska zgodovina $\mathrm{v}$ prostoru in času oblikovala diferencirano na nek način sledeč selitvi centrov. Od jugovzhodne Evrope proti južni in jugozahodni Evropi, zahodnim območjem in Zahodni Evropi, kjer so se ustalile posamezne zvrsti, glasbeniki, kompozicijske tehnike in glasbene kulture. Od srednjega veka naprej je bila Srednja Evropa refleksija tega kot meja zahodno-vzhodnega verskega konflikta. Vedno intenzivneje je bila vključena v evropski prednostni razyoj. Od posvetne enoglasne pesmi $\mathrm{k}$ večglasju. $\mathrm{Z}$ odločilnim prispevkom k cerkveni pesmi je Srednja Evropa posebno med 18. in 20. stoletjem zavzemala vedno pomembnejši položaj v evropskem razvoju. Regionalna, nacionalna, univerzalna in individualna slogovna območja so se začela med seboj prekrivati in Srednja Evropa je postala talilnik omenjenih komponent. Raziskovanje glasbene zgodovine je bilo do danes skoraj izključno vezano na umetno glasbo, vendar je slednjo nemogoče dojeti 


\section{MUZIKOLOŠKI ZBORNIK • MUSICOLOGICAL ANNUAL XL}

uropa wurden zu einem Schmelztiegel dieser Komponenten. Die Musikgeschichtsforschung ist bis heute fast ausschließlich auf die Kunstmusik ausgerichtet, diese aber ohne die Popularmusik und Volksmusik zu begreifen und zu verstehen ist unmöglich. Diese soziale, kulturelle und Gattungsschichtung gilt nicht nur für das 20. Jahrhundert, denn die entsprechende innerlich differenzierte Musik war ebenso bedeutend im Mittelalter, wie auch im 18. und 19. Jahrhundert. Mitteleuropa wurde und wird immer noch in einer europäischen Radposition betrachtet, das überhaupt nicht zutrifft, denn dieser Raum brachte im Laufe der ganzen Musikgeschichte Europas permanent neue Elemente, stilistische Anregungen, ebenso wie wichtige Synthese zustande. Der derzeitige Stand und die Forschung mindestens des letzten Jahrhunderts konzentriert sich vorrangig auf die Rekonstruktion des Werdeganges der einzelnen Landes- und Nationalkulturen. Dies geschiet im Schrifttum in den Nationalsprachen veröffentlicht. Deshalb wird ein wesentlicher Teil von der internationalen musikwissenschaftlichen Forschung ignoriert. Sprachliche Grenzen bestimmen das Unverständnis und die geringe Akzeptanz der musikalischen Länderforschungen. In den 90er Jahren etablierte sich in Mitteleuropa immer stärker eine internationale Musikforschung, die sich nationalen und internationalen Themen der Musik des 16. und 17. Jahrhunderts, ebenso wie der Musik des 18. Jahrhunderts widmete. Die Neue Musik wird zu einem immer wichtigen Teil der Untersuchungen, gefördert durch spezialisierte Festivals und Tagungen. Die Internationale institutionelle Zusammenarbeit ist die einzige Möglichkeit, ein objektives und wahrheitsgetreues Bild über Musikentwicklung in Mitteleuropa zu erlangen. in razumeti brez popularne in ljudske glasbe. Ta socialna, kulturna in zvrstna plast ni pomembna zgolj za 20. stoletje. Ustrezno notranje strukturirana glasba je bila enako pomembna v srednjem veku, kakor tudi v 18. in 19. stoletju. Srednja Evropa je bila in je še vedno opazovana v splošno evropskem kontekstu, kar sploh ni pravilno, saj je ta prostor tekom celotne glasbene zgodovine prinašal nenehno nove elemente, slogovne ideje, kakor tudi dosegel pomembno sintezo. Sedanje stanje in raziskovanje najmanj zadnjega stoletja, se prednostno osredotoča na rekonstrukcijo razvoja posamezne dežele in nacionalnih kultur. Raziskave so objavljene v nacionalnih jezikih, zato je ignoriran pomemben del mednarodnega muzikološkega raziskovanja. Jezikovne meje pomenijo nerazumevanje in slabo sprejemanje lokalnih glasbenih raziskav. V 90. letih se je v Srednji Evropi vedno močneje etabliralo mednarodno glasbeno raziskovanje, ki je posebno pozornost namenilo nacionalnim in internacionalnim temam v glasbi 16 . in 17 . stoletja, kakor tudi temam v glasbi 18. stoletja. Nova glasba postaja vedno pomembnejši del raziskovanj, ki jih pospešujejo specializirani festivali in simpoziji. Mednarodno institucionalno sodelovanje se zdi edina možnost za sestavo objektivne in resnične podobe o glasbenem razvoju v Srednji Evropi.

1. Eine kurze Siedlungs- und Entwicklungsgeschichte: Ist die Abgrenzung Mitteleuropas geographisch, kulturell und politisch möglich?

Mitteleuropa ist weder geographisch, kulturell, politisch noch ethnisch klar abgrenzbar und einheitlich. Der Raum war und ist nach allen Seiten offen, für kulturelle, machtpolitische und wirtschaftliche Einflußnahmen. ${ }^{1}$ Zusätzlich war Mitteleuropa

\footnotetext{
1 Dieser Umstand führte zu terminologischen Unstimmigkeiten, die bei solchen Projekten auftreten. So untersucht in einem Beitrag z.B. Rudolf Jaworski, Zentraleuropa - Mitteleuropa - Ostmitteleuropa, in: Newsletter Modern 2., H.1., März 1999, 2-4, die anwendbaren Begriffe. Für ihn ist der deutsche Begriff Mitteleuropa suspekt. Er will durch sein Vermeiden dem Anschein eines deutschen und österreichischen Kulturträgersyndroms aus dem Wege gehen. Andererseits ist der Begriff L`Europe Central, Central Europe oder der tschechische Begriff "Střední Evropa " für ihn akzeptabel. Das zeigt, daß Konvention, Konzepte der Vergangenheit und politische Hierarchien, die sprachlich und begrifflich lavieren immer noch unseren Zugang zu diesem Raum bestimmen. In demselben Heft der Zeitschrift Newsletter Moderne
} 
eine Pufferzone für alle anstürmenden Völkerschaften aus dem östlichen Raum, den asiatischen und uralischen Völkern des Mittelalters, dem Druck tatarischer und mongolischer Eroberer ausgesetzt. Vorher waren es die Horden der Hunnen, Avaren und der magyarischen Stämme, die durch den mitteleuropäischen Raum nach Westen drängten. Es war die Zeit einer permanenten Verunsicherung Mitteleuropas. Von den Ostvölkern blieben nur die Magyaren im mitteleuropäischen Raum. Sie kehrten nach ihrer vernichtenden Niederlage 955 auf dem Lechfelde nach Mitteleuropa zurück und wurden hier seßhaft. Vor dieser Periode waren es neben den vielen ethnisch unbenennbaren und undefinierbaren Völkerschaften aus der frühgeschichtlichen Periode, vor allem die Kelten, ${ }^{2}$ als klar zu kennzeichnendes und europaweit verbreitetes Ethnikum, mit ihren wichtigen mitteleuropäischen Zentren, denen von der Archeologie und Kulturgeschichte eine immer größere Aufmerksamkeit zugewandt wird. Auch im Bezug auf ihre spezifischen kulturellen und musikalischen Besonderheiten. ${ }^{3}$ Ihnen folgte der Aufbau des trennenden römischen Limes, der umgekehrt eine klar umrissene Begrenzungsfunktion hatte, quer durch Mitteleuropa verlief und den Schutz vor den nach Süden und Südosten drängenden germanischen Stämme der Quaden and Markomanen bieten sollte. Seine Funktion war es, den mitteleuropäischen Provinzen Roms und ihren Besitztümern eine Abschirmung zu gewähren. Gerade der Limes und ähnliche Schutzwälle sind für die mitteleuropäische Archeolo-

widmen sich auch Beiträge anderer Autoren dieser Thematik, wie Heidemarie Uhl, Peter Stachel u.a. Siehe auch Jaques Le Rider, Mitteleuropa. Auf den Spuren eines Begriffes, Essay, Wien 1994; Urs Altermatt (Hg.), Nation, Ethnizität und Staat in Mitteleuropa, Wien, Köln, Weimar 1996. Eine Scheidung zwischen Ostmitteleuropa und Westmitteleuropa wird praktiziert. Der Begriff einer Übergangszone zwischen West- und Osteuropa wird ebenfalls strapaziert, um einer nötigen spezifischen kultur-geographischen Klärung aus dem Wege zu gehen. Letztlich wird dieser Raum nicht nur begrifflich in Frage gestellt, sondern seine Existenz bezweifelt, wie es Timothy Ash tut, in seinem Beitrag: Does Central Europe exist?, in: New York Review of Books 9. 10, 1986, 45-54, was letztlich die Absurdität dieser Fragestellung aufzeigt. Aus dem Blickwinkel Ash's, über den Atlantik, ist wohl Mitteleuropa ins Mikroskopische geschrumpft. Auch der schwedische Diplomat Ingmar Karrsson verfaßte einen Beitrag mit dem Titel: Stredná Európa medzi snom a skutočnoseou (Mitteleuropa zwischen Traum und Wirklichkeit), in: OS Fórum občianskej spoločnosti H.7 Jún, Bratislava 1997, 21-25, und oszilliert zwischen einer virtuellen und realen Welt Mitteleuropas. Das Interesse gegenüber Mitteleuropa ist aus transatlantischer Sicht, ebenso wie aus Großbritannien, aber auch Deutschland und Österreich im letzten Jahrzehnt angewachsen. Manchmal sieht man, daß es eine wirkliche Entdeckungsreise ist, oft in einen ganz unbekannten Teil Europas. Dies bezieht sich auf die Wirtschaft, die Geschichte, die Sozialstruktur, die politische, philosophische, nationale, ethnische, kulturelle und ideologische Grundlage. Das Verständnis für diese kulturgeographische Region ist in diesen Werken häufig zweifelhaft, denn Mitteleuropa bleibt für sie weitgehend eine terra incognita. Was bei der komplizierten Geschichte des Raumes nicht überraschend ist, insbesondere wenn man mit vorgeformten Meinungen und einer beschränkten Kenntnis an die Interpretation selektiver und fragmentarer Fakten herangeht. Wie wenig zutreffend solche Geschichtsbilder auch von Forschern mitteleuropäischer Provenienz sein können, zeigt die Monographie von Piotr Wandycz, Střední Evropa v djinách od středovku do současnosti (Mitteleuropa in der Geschichte vom Mittelalter bis zur Gegenwart), Academia Praha 1998 (ursprüngliche englische Oririganausgabe: The Price of Freedom, A History of East Central Europe from the Middle Ages to the Present, Routledge London 1992).

2 John Haywood, Die Zeit der Kelten, Zweitausendeins Frankfurt a.M. 2003.

3 František Zagiba, Von der keltischen Carnyx I zum Alphorn, in: Festschrift für Walter Wiora, ed. L.Finscher, Kassel Bärenreiter 1967, 609-612; Albrecht Schneider, Orale Tradition, Musikgeschichte und Folklorismus in Irland. Das Kontinuitätsproblem und die historische Volksmusikforschung, in: Historische Volksmusikforschung, Hg. A. Mauerhofer mit J. Bezić, Graz 1981, 117-157. (= Musikethnologische Sammelbände 5). Auch hängen diese Fragen mit der gesamteuropäischen instrumentenkundlichen Vorgeschichte zusammen, wie darauf verwiesen wird; siehe Albrecht Schneider, Die Megalithkulturen in Westeuropa - eine Quelle zur Frühgeschichte der Musik? in: Studia Musicologica 15, Budapest 1973, 205-223. 
gie eine dauernde Herausforderung, seine verbindende ebenso wie trennende Funktion zu untersuchen. ${ }^{4}$

In die östliche Richtung strebte im Mittelalter die Expansion der Bayern und Franken. Vom 4.-6. Jahrhundert war Mitteleuropa ein von den slawischen Völkern am kompaktesten besiedelter Raum, der von Karantanien bis nach Zentralösterreich sowie noch weiter in das Sorbische, das Pommerische an die Ostsee und nach Nordwesteuropa reichte. Nicht zu erwähnen die kurzzeitigen frühmittelalterlichen Völkerwanderungen, die diesen Raum nach dem Macht- und Raumverlust Roms zumindest kurzzeitig überquerten und ihn in Schutt und Asche legten (etwa die Langobarden, Goten, Gepiden u.a.). Vom Südosten waren hier im Frühmittelalter die Interessen des Bulgarenreiches vertreten und später auch jene von Byzanz. ${ }^{5}$ Ihr Einflußgebiet reichte in der Karolingerzeit im 8. Jahrhundert bis Mitteleuropa, wo die Karolinger vor allem versuchten die Macht der Awaren durch massive kriegerische Feldzüge zu unterbinden. Dann folgte die Gründung der ersten Slawenreiche überhaupt, uzw. in Mitteleuropa. Anfang des 7. Jahrhunderts jenes von Samo, im beginnenden 9. Jahrhundert des Fürstentums von Pribina in Nitra; weiter war es jenes Reich am Plattensee in Pannonien gegründet, nach der Vertreibung von Pribina, mit seinem Sohne Kocel. Das mährisch-slowakische Fürstenreich mit Zentren in Nitra und dem mährisch-slowakischen Grenzgebiet umfaßte als Kernregionen die Flußgebiete der March, der Waag und Nitra, mit den Herrschern Mojmír, Svätopluk u.w. Im 13. Jahrhundert war Mitteleuropa das Zielgebiet von Plünderungen der Tataren und im 16. Jahrhundert kam es zu seiner teilweisen Einvernahme durch das osmanische Reich. Seine Grenzen verliefen an der Schwelle der Südslowakei und zu Ostösterreich. Die Krieferischen Einfalle trieben Flüchtlingsströme von Exulanten vor sich her, die vom Balkan und Südosten nach Mitteleuropa flüchteten - in größter Zahl die Kroaten. ${ }^{6}$ An den unruhigen Grenzen des osmanischen Reiches, nach ihrer Okkupation des Balkans und des von Magyaren und Slowaken besiedelten Pannoniens, standen die Türken mehr als zwei Jahrhunderte vor den Toren Wiens, des Burgenlandes und der Slowakei. Nach den langjährigen Überfällen der tatarischen Horden im 13. Jahrhundert, folgten kurz darauf spätgermanische Kolonisationen und Landnahmen, vom 13. Jahrhundert an massiv durch den Deutschen Orden (Ritterorden) ${ }^{7}$ gefördert. Sie kennzeichneten eine weitere Phase von wirtschaftlichen und politischen Expansions- und Landnutzungsinteressen in Mittel- und Ostmitteleuropa, die in west-östlicher Richtung verliefen. ${ }^{8}$ Ebenso dauerten über 400 Jahre, vom 13.-16. Jahrhundert,

${ }^{4}$ Es ist eine Reihe von archeologischen Konferenzen zu diesem Thema der römischen Grenzziehungen, die von der Österreichischen Akademie der Wissenschaften, der Slowakischen Akademie der Wissenschaften u.a. Partnerinstitutionen und Universitäten in einem 4-5 Jahreszyklus europaweit organisiert wurden (bis heute 17 Konferenzen), siehe z.B. :Valerie A. Maxfields \& Michael Dolson (Hg.), Roman Frontiers Studies 1989, University of Exeter Press Reed Hall 1991.

5 Alexander Avenarius, Byzantská kultúra v slovanskom prostredív VI-XII. storočí. K problémom recepcie a transformácie (Byzantinische Kultur im slawischen Milieu im VI.-XII. Jh.), VEDA Bratislava 1992.

6 K. Kučerová: Chorváti a Srbi v strednej Európe (Kroaten und Serben in Mitteleuropa), Bratislava 1976; Ján Botík, Chorváti na Slovensku (Kroaten in der Slowakei), Bratislava 2002.

7 Uwe Ziegler: Kreuz und Schwert, Die Geschichte des Deutschen Ordens, Wien. Köln, Weimar Böhlau 2003.

8 Diese Fragen wurden auf einem Internationalen workshop 2002 in Wien behandelt, gestützt auf das Thema: Die Habsburgermonarchie: ein Ort der Inneren Kolonisierung? 
die aus dem Südosten über die Karpaten migrierenden Hirtenkolonisationen, die unterschiedliche ethnische und soziale Schichten nach Zentraleuropa führten. ${ }^{~}$ Dieser kurze Überblick zeigt die komplizierte ethnische, soziale und politische Formung Mitteuropas und die dynamisch sich verändernde Situation bis in die Neuzeit, die zweifelsohne die musikalische Ausprägung beeinflußte. Hier muß die mitteleuropäische Archeologie und Frühgeschichtsforschung angesprochen werden um klärende Analysen, vor allem was das Musikinstrumentarium dieser Völkerschafften betrifft, mitzubestimmen. Wir müssen bei diesen Bewegungen zwischen einer äußeren und inneren Kolonisation unterscheiden. Unter den externen gab es die geringeren Umschichtungen z.B. mit den Habanen und Hugenotten, den Kroaten und südosteuropäischen Hirten. Zur internen Kolonisationen gehören die Husiten, die Tschechischen Brüder, die Bewegung der Ungarn nach Norden, in die Slowakei, der Slowaken nach Mittelosteuropa u.w., die verständlicherweise ihre eigenen musikalischen Kunstgattungen - etwa die Kirchenlieder, ebenso wie volksmusikalische Traditionen mitbrachten.

Im mitteleuropäischen Raum kreuzten sich im Hoch-, im Spätmittelalter, und bis zur Neuzeit, zahlreiche Migrationsströme, Interessen und Expansionsprozesse. Sie wurden allmählich ethnisch und kulturell integriert und assimiliert. Die permanenten Religions-, Reformations- und Gegenreformationskriege entsiedelten weite Landstriche Mitteleuropas und leiteten demographische Umstrukturierungen ein. Nach der Zurückdrängung der Türken im 18. und 19. Jahrhundert folgten aus dem mitteleuropäischen Raum Kolonisationsströme nach Südosten. So kamen Hunderttausende Slowaken in die entsiedelten und demographisch entleerten Räume nach Ungarn, Rumänien, Kroatien, Serbien, Bulgarien, in die Ukraine usw. ${ }^{10}$ All dies war begleitet von soziokulturellen Umschichtungen, ebenso wie mit den integrierenden und machtpolitischen Expansionsinteressen der Habsburger. Sie waren in der Neuzeit mit permanenten wirtschaftlichen Kolonisierungs-, Zersetzungs- und Assimilierungstendenzen verknüpft. Diese sind insbesondere im österreich-ungarischen multiethnischen Staatsgebilde des 18. und 19. Jahrhunderts weiter eskaliert, und erreichten Ende des 19. Jahrhunderts ein unerträgliches Maß an machpolitischem Zentralismus, Unterdrückung und Dirigismus. Sie repräsentierten eine spezifische mitteleuropäische Variante einer ethnischen und wirtschaftlichen Kolonial-, Assimilierungs- und Unterwerfungspolitik. Sie wurden mit allen Mitteln einer Universalisierung und Gleichschaltungspolitik verwirklicht. Diese strebte zur Durchsetzung einer österreichisch-

9 Ihre Erforschung wurde von 1958 an von der Internationalen Kommission für die Erforschung der Karpaten und des Balkans geleitet, und in ihrer Zeitschrift Carapato-Balcanica (Bratislava u.w. 1958-) reflektiert. Sie organisierte eine Vielzahl internationaler Konferenzen und Symposien und die ihnen entsprechenden Veröffentlichungen. Auf diese bezog sich das Projekt: Oskár Elschek, Volksmusik und Volksmusikinstrumente der Karpaten und des Balkans Prinzipien eines interkulturellen Forschungsprojektes, in: Studia instrumentorum musicae popularis VIII, Stockholm 1985, 63-66.

${ }^{10}$ Zu dieser Problematik sind eine Reihe von kartographischen Veröffentlichungen zwischen 1998-2003 erschienen. Vorerst Slovenský etnografický atlas, VEDA Bratislava 1990, in den folgenden Jahren mit selbständigen ethnololgischen Atlasausgaben der Slowaken im heutigen Ungarn, der Ukraine, Kroatien, Serbien, Polen und Rumänien; Mojmír Benža, Kartografická metóda a slovenská etnológia (Die kartographische Methode und slowakische Ethnologie), Bratislava 2001. 
ungarischen Reichsideologie, im Sinne einer mitteleuropäisch assimilierenden Vereinheitlichung der hier Jahrhunderte lebenden multiethnischen Gesellschaft, vor allem der slawischen Völker. Auch letztlich mit dem Resultat, daß dieser Raum nach vielen europäischen Erbfolge- und Dynastiekriegen, lokalen und regionalen kriegerischen Auseinandersetzungen und Aufständen im 17.-19. Jahrhundert einem Auflösungsprozeß unterlag. Letztlich war dieser Raum im 20. Jahrhundert der Ausgangspunkt und Auslöser von zwei verherrenden Weltkriegen. ${ }^{11}$ Diese führten schritt- und zwangsweise zur Auflösung dieser Vorherrschaftsideen, und im 20. Jahrhundert zur Fragmentierung und Aufspaltung des mitteleuropäischen Raumes in überwiegend nationalstaatliche Gebilde. ${ }^{12}$ Es wirken alte nationale Spannungen und politische Implikationen und Vorstellungen auch heute noch nach. Wir stehen heute in Mitteleuropa, aber nicht nur in Mitteleuropa, erneut vor Versuchen einer gleichschaltenden kulturellen Globalisierung, die alle Lebensbereiche erfassen soll. ${ }^{13}$ Beseelt von einer Einheitsidee, mit alten Vorstellungen auf die Fahne geheftet, unterstützt durch altneue Aktivitäten, entsprechend den Wunschträumen gescheiterter geschichtlicher Großmachtvisionen. Mit Versuchen diese antiquierten Vorstellungen in restitutive Bahnen zu lenken und kulturpolitisch umzusetzen. ${ }^{14}$ Auch wenn heute diese staatspolitischen Prozesse der Habsburger Monarchie mit einer kritischen Distanz betrachtet und analysiert werden, so sind ihre Nostalgiker und Nachfolgewirkungen immer noch präsent. ${ }^{15}$ Eine eigene Problematik ergibt sich aus den Entwicklungen der Zwischenkriegsperiode, in den nachfolgenden Kriegsjahren, und den massiven politischen, sozialen und kulturellen Veränderungen, die in Mitteleuropa Ende der 40. Jahre einsetzten. Mit einer nachfolgenden 40 jährigen, sehr turbulenten Zeit an der Bruchstelle eines machtpolitisch geteilten Europas, das kaum seine Geschicke selber lenken konnte. In einer Periode, die 1989 abgeschlossen wurde. Die erwähnten Widersprüche des vorhergehenden Jahrhunderts wurden in die 90er Jahre übertragen. ${ }^{16}$ Wesentlich ist der Aufstieg der heimischen wissenschaftlichen historischen, inklusive der musikwissenschaftlichen Forschungen in den mitteleuropäischen Ländern, die eine eigenständige Interpretationsweise ihrer eigenen Geschichte im emischen, "insider" Sinne anstreben.

Diese Tatbestände, als das Resultat einer 1500 Jahre währenden regionalen, ethnischen und nationalen Entwicklung, sind zweifelsohne eine Herausforderung, sich

${ }^{11}$ Inka Mülder -Bach (Hg.), Modernität und Trauma. Beiträge zum Zeitumbruch des Ersten Weltkrieges, WuV Wien Parabasen 2002.

${ }^{12}$ Karl Acham und Katharine Scherke (Hg.), Kontinuitäten und Brüche in der Mitte Europas. Lebenslagen und Situationsdeutungen in Zentraleuropa um 1900 und 2000, Wien Passagen 2003.

${ }^{13}$ Ulrich Beck, Politik der Globalisierung, Frankfurt a. M. 1998; derselbe: Perspektiven der Weltgesellschaft, Frankfurt a. M. 1998.

${ }^{14}$ Alfred Payrleitner, Österreich und Tschechen. Alter Streit und neue Hoffnung, Wien Böhlau 2003; Fritz Fellner, Geschichtsschreibung und nationale Identität. Probleme und Leistungen der österreichischen Geschichtswissenschaft, Wien Böhlau 2002.

${ }^{15}$ Peter Karoshi, Einheit in der Vielfalt? Pluralität und Ethnizität in den staatserhaltenden Narrativen des habsburgischen Reiches, in: Newsletter Moderne 6, H.1., März 2003, 14-18.

${ }^{16}$ Hans-Joachim Veen (Hg.), Nach der Diktatur. Demokratische Umbrüche im Europa des 20. Jahrhunderts, Böhlau Weimar Köln 2003. Der Sammelband zeigt eine sehr differenzierte Art, wie mit den politischen Gegebenheiten in den einzelnen Ländern Mitteleuropas umgegangen wurde. Also weit entfernt von einer einheitlichen ideologisch-politischen Realität, wie das meist vereinfachend angenommen wird. 
intensiv mit dem wahren geschichtlichen Werdegang von Zentraleuropa zu beschäftigen. In diesem Sinne ein objektiveres Bild über ihre Vergangenheit anzustreben. ${ }^{17}$ Nur an eine solche kann die Musikwissenschaft in ihren Analysen und Darstellungen anknüpfen. Ihre Bedeutung liegt im Bestreben die Gegenwart besser zu verstehen. Es ist unmöglich sich des geschichtlichen Vermächtnisses dieses Raumes zu entledigen, wie groß oder umfassend wir ihm auch verstehen mögen. Denn die Geschichte ist Teil unseres Alltagslebens, unserer Verhaltens- und Denkweise. Ich meine hier die wahre, nicht die manipulierte und die selektiv subjektive und ideologisch interpretierte Geschichte. Nicht jene der überholten politischen Wunschträume und einer zurechtgebogenen Geschichte, sondern die Untersuchung des entscheidenden, reichen und vielgestaltigen gedanklichen und mentalen Erbes dieses Raumes. Des Raumes, der im letzten Jahrzehnt eine so große Beachtung seitens der Historiker, Politiker, Kunsthistoriker, Ökonomen, Ideologen und auch der Musikhistoriker in allen Weltteilen erfahren hat. Erneut verstanden als ein Grenzgebiet des europäischen Raumes. Mit einer eigenständigen Geschichte, und einer Geschichte, die in allen wichtigen Entwicklungen Europas eine nicht unbedeutende Rolle spielte. Mitteleuropa ist keine Randzone Europas, wie das häufig pertraktiert wird, sondern ein Zentrum, oder zumindest eines der zahlreichen, gleich wichtigen, sich wandelnden und entscheidenden Zentren der europäischen geschichtlichen Entwicklung.

Es gibt heute in die Hunderte gehende Monographien, Zeitschriften, Sammelbände, Projekte und Serien über Mitteleuropa, auch von Forschern außerhalb von Zentraleuropa verfaßt, die sich mit den Problemen ihrer politisch-staatlichen, geographisch-ökonomischen, kulturgeschichtlichen und national-ethnischen Abgrenzung beschäftigen. ${ }^{18}$

${ }^{17}$ Michaela Marek, Kunst und Identitätspolitik. Architektur und Bildkünste im Prozesse der tschechischen Nationalbildung, Böhlau Wien, Köln, Weimar 2003; Svjatoslav Pacholkiv, Emanzipation durch Bildung. Entwicklung und gesellschaftliche Rolle der ukrainischen Intelligenz im habsburgischen Galizien (1790-1914), Verlag für Geschichte und Politik Wien, Oldenburg Wissenschaftsverlag München 2002.

${ }^{18}$ Hier sei auf die in München konzentrierte Südosteuropa-Forschung hingewiesen, wie auch die immer intensiver betriebene editorische und Forschungsarbeit in den Publikationen der Cambridge University (der Serie Cambridge Studies in Contentious Politics und Cambridge Studies in Comparative Politics), wie auch auf die bei Böhlau und in anderen spezialisierten Verlagen erscheinenden Publikationen hingewiesen. Es sind dies die Ausgaben: Südosteuropa aktuell, Südosteuropa Mitteilungen, Vierteljahrschrift der Südosteuropa-Gesellschaft, Südosteuropa Jahrbücher, Südosteuropa-Studien, Südosteuropa-Schriften, Weitere Veröffentlichungen und Ausgaben: Ulrike Hirschhausen (Hg.), Nationalismen in Europa: West- und Osteuropa im Vergleich, Göttingen 2001, wobei in diesen und ähnlichen Arbeiten Mittelund Osteuropa aus der Sicht antiquierter und überholter Interpretationen behandelt wird, vor allem aus der Sicht nationalistischer und postkolonialer Modelle, in welchen Westeuropa eine demokratisierende Missionsrolle zugewiesen wird, wie das vor Jahrzehnten der Fall war. Das europäische- und westeuropäische ethnozentrische Modell gilt als eine Art "Leitkultur", über deren dubiosen Inhalt im Vorjahr Diskussionen in Deutschland und in den Vereinigten Staaten ernsthaft geführt wurden. Im Sinne einer neuen sich etablierenden Weltmachtrolle. Zu Arbeiten mit diesen Vorstellungen gehören z.B. folgende: Spring Ulrike, Granqvist Karin (ed. 2001): Representing Gender, Nation, Ethnicity in Text and Image. Kvinnfork (= Kvinnforsk Occasional Papers). Historische Konzepte werden in der folgenden Arbeit besprochen: Geppert Alexander C. T., Passerini Luisa (Hg.): European Ego-Histories: Historiography and the Self, 1970-2002. Athen/River Vale, New Jersey 2001. Außer Deutschland und insbesondere Bayern widmen sich auch weitere Länder diesen Auseinandersetzungen, wie England und die Vereinigten Staaten. Auch in Mitteleuropa wirken Institutionen mit solchen Einstellungen, wie z.B. in Wien das gegründete Institut für den Donauraum, mit der Zeitschrift Der Donaraum und mit weiteren Forschungsprojekten, z.B. Identitätswandel im veränderten Europa. Nationale und kulturelle Identitäten Österreichs (1995), Manfred Wagner (Hg.): Supranationalität, Internationalität, Regionalität. Kulturvergleiche, Wien IFK 1994 (Internationales Forschungszentrum Kulturwissenschaften). In die Reihe dieser Institutionen gehören auch folgende: Euroregion Karpaten, Carpathian Foundation, Association for the Carpathian Regional Universities. Bevorzugte Themen sind bei diesen Institutionen z.B. Der Südosteuropa-Stabilitätspakt- 
Läßt man diese historischen Prozesse, die ich kennzeichnete, Revue passieren, mit allen komplizierten und katastrophalen Folgen, mit ihren inherenten Herausforderungen, Widersprüchen und gestaltenden Kräften, dann muß man sich fragen: Was hat dieser Raum kulturell geleistet? War er für solche subtile künstlerische Entwicklungen und Kontinuitäten, wie sie die Musik darstellt überhaupt geeignet und ertragsreich? Ich möchte versuchen dies in einigen knappen Gedankengängen zu beantworten.

Es ist ersichtlich, daß die allgemeingeschichtliche als auch die regionale Geschichte Europas außerordentlich intensiv untersucht wird. Über die Musik gibt es aus diverser Sicht kaum ein so umfangreiches Schrifttum und auch die vorliegenden Untersuchungen weisen einen beschränkteren kulturregionalen Rahmen auf. Vor allem Versuche einer überregionalen vergleichenden Musikforschung, welche die jeweiligen angrenzenden Räume in ihre Analysen einbeziehen. ${ }^{19}$

Es stellt sich die Frage, weshalb bei der zentralen Behandlung musikalischer und musikgeschichtlicher Fragen der Geschichte und den geschichtswissenschaftlichen Resultaten eine so große Aufmerksamkeit gewidmet wird? Musik ist zweifelsohne ein unabdingbarer Teil der Kunst- und der Sozialgeschichte. Will man die Musikgeschichte mit allen ihren Motivationen und Stilveränderungen über lange Zeiträume hindurch begreifen, dann müssen ihre sozialgeschichtlichen und politischen Implikation mit berücksichtigt werden. Auch wenn die Musik ihre eigene Geschichte, ihre eigenständige künstlerische und ästhetische Kontinuität besitzt, so ist sie ein Sozialund Kulturphänomen, mit einer weiterreichenden Bedeutung und Einflußnahme auf andere Sozialphänomene, die sie permanent mitbestimmt aber auch reflektiert. Dies gilt im allgemeinen, ebenso bei einzelnen Geschichten und Musikgeschichten Mitteleuropas. Wie das in Mitteleuropa der Fall ist, so ist es in allen anderen europäischen Regionen. Je intensiver wir diese Regionalgeschichten verstehen, umso besser werden wir auch Europa in seiner Gesamtheit verstehen.

bisher erreichte und bleibende Aufgaben (Vorsitzender des Projektes Gróf Andreas Wass von Czege). Das Institut für Slavistik in Leipzig organisierte eine "Exkursion", mit einem nachfolgenden Bericht: Die Karpaten - zwischen subregionaler Identitätssuche und EU-Osterweiterung. Für die erwähnten Projekte stehen umfangreiche Geldmittel zur Verfügung, die im Widerspruch zu den laufend herabgesetzte Ausgaben für die heimischen wissenschaftlichen Forschungen in den mitteleuropäischen Ländern stehen. Dies gilt insbesondere für die Slowakei. Hier werden vor allem ideologische und politologische Projekte gefördert, durch die Gründung neuer Zeitschriften, wie die folgende: Kafka - Časopis pro stYceední Europu, der von Inter Nationes in Berlin in mittleuropäischen Sprachen veröffentlicht wird. Einige Monographien aus der Serie der Oxford University spielen eine ähnliche Rolle, wie die angeführten Werke: Christoph Knill, Europeisation of National Administration. Cambridge University Press Cambridge 2001; Alan Mayhew, Recreating Europe. The European Union's Policy Toward Central and Eastern Europe 2. Ausg. CUP Cambridge 2001; Zoltan Barany, The East European Gypsies. Regime Change, Marginality and Ethnopolitics, CUP Cambridge 2001; Roger Peterson, Resistance and Rebellion. Lessons from Eastern Europe. CUP Cambridge 2001; Alica Techova, Herbert Matis, Jaroslav Pátek, (Hg.), Economic Change and the National Question in Twentieth-Century Europe. CUP Cambridge 2001- eine Arbeit die sich mit der ehemaligen Sowjetunion, Jugoslawien, der Tschechoslowakei, ebenso mit Beglien, Spanien, Finnland, der Schweiz auseinandersetzt, die ähnliche sich überschneidende ethnische und wirtschafliche Probleme zu bewältigen haben.

${ }^{19}$ So wie das z.B. im Sammelband geschehen ist, der mittel- und südeuropäische Prozesse kennzeichnet: Stanislav Tuksar (Hg.), Zagreb and Croatian Land as a Bridge between Central-European and Mediterranean Cultures, Croatian Musicological Society Zagreb 1998. 
MUZIKOLOŠKI ZBORNIK • MUSICOLOGICAL ANNUAL XL

\section{Europa - Mitteleuropa, die Zentrenwanderungen der europäischen Musikkulturen}

Die europäische - oder die vermeintliche gesamteuropäische Musikgeschichte ist keine kontinuierliche Stilgeschichte, weder in ihrer Raum- und Stilverteilung noch in ihren kennzeichnenden Gattungen. Sie beruht auf Zentren und Kulturmigrationen, determiniert durch gesamthistorische Raum- und Kulturkontakte, die ihre Besonderheiten besitzen und ihre eigenen Wege gingen, um sich dann allmählich in einem Gesamtverbreitungsbild der europäischen Musik zu finden.

Die entscheidenden Räume der Musikentwicklung von der griechischen und römischen Antike, bestimmt durch vorderorientalische Einflüsse und außerhalb von Europa generierte Beziehungen, blieben für das gesamteuropäische Mittelalter maßgebend und stimulierend, bis sich aus der spätantiken römischen und byzantinischen Tradition neue christliche liturgische Gesänge formten - vereinfachend als gregorianischer Gesang bezeichnet. Durch sie kam es in der europäischen Musik zu einer neuen entscheidenden Wende und kennzeichnenden Gattungsgründung. Im Osten entfaltete sich parallel und kontinuierlich die orthodoxe Tradition der Kirchenmusik, als frühmittelalterliche Gattung des Kirchengesanges. Beide Traditionen erhielten für die nachfolgenden Jahrhunderte die Bedeutung eines universalen europäischen Musikerbes, für den einstimmigen und mehrstimmigen Gesang. Am Schnittpunkt Mitteleuropas trafen sich beide Traditionen, als die geistigen, liturgischen und musikalischen Nachfolger des weströmischen und oströmischen Reiches. Vor allem in der Mission der Slawenbrüder, des Hl. Method und Kyril, entsandt von Byzanz auf mitteleuropäischen Wunsch, des hier im 9. Jahrhundert etablierten Slawenreiches. ${ }^{20} \mathrm{Nach}$ einer sehr intensiven und erfolgreichen Missionsarbeit unterlagen sie in ihrer neugestalteten altslawischen Liturgie und Gesang im Kampf gegen die Kirchen- und Reichsinteressen der Franken und Bayern. Diese unterstützten die zentralistischen Bestrebungen Roms und zogen daraus ihren machtpolitischen Nutzen. Die Slawenbrüder verrichteten ihre kulturelle Missionsarbeit in der Slowakei (auch durch die Gründung der slawischen Schrift und Schriftsprache, der Zobor Klosterschule u.a.), und nachfolgend in Mähren, Polen und Böhmen. Diese Missionsarbeit setzten ihre Schüler bei den Slawen in Südosteuropa fort. Sie stellten die bestimmenden Weichen für die Entwicklung der christlichen Kultur- und Musiktradition des kommenden Jahrtausends im mittel- und mittelosteuropäischen Raum. ${ }^{21}$

Die weltliche Liedgattung des Mittelalters, als die epische Volks- und historische Tradition, das Sagen- und Heldenlied, war mehr in anderen europäischen Regionen beheimatet - in Nord-, Ost- und Südeuropa. Man versuchte solche auch anderwärts nachzuweisen und zu rekonstruieren - mit Ossian in Irland, oder auch im Konzept einer böhmischen Epik. ${ }^{22}$ Diese änderten aber nichts an der Tatsache, daß diese Gat-

\footnotetext{
${ }^{20}$ Franz Zagiba, Musikgeschichte Mitteleuropas I. Verband der wissenschaftlichen Gesellschaften Österreichs. Wien 1976, S. 81 u.w.

${ }^{21}$ Ladislav Mokrý (Hg.), Anfänge der slawischen Musik, Verlag der Slowakischen Akademie der Wissenschaften. Bratislava 1966; JiYí Vysloužil, Rudolf Pečman (Hg.), Music of the Slavic Nations, Česká hudební společnost. Brno 1981.

${ }^{22}$ Vladimír Karbusicky, Anfänge der historischen Überlieferung in Böhmen, Böhlau Verlag Köln Wien 1980.
} 
tung nicht die zentrale Domäne der mitteleuropäischen Entwicklung war. Auch wenn alte Traditionen der Sagen, der mythologischen und historischen Epik gerade im mitteleuropäischen Raum - im Österreichischen, zumindest ebenfalls dokumentiert sind - im passauischen und salzburgischen Regionalbereich. Auch die geistlichen und weltlichen Historien-, die durch sie geprägten epischen und lyrischen Gattungen. Sie waren in Südwesteuropa zentriert und durch maurische Einflüsse im Kastilianischen und Provenzalischen mit gestaltet. ${ }^{23}$ Sie umfaßten den mitteleuropäischen Raum nicht als ihren zentralen, waren aber zweifelsohne Mitgestalter der sich im süddeutschen und österreichischen Kulturbereich entwickelnden Minneliedern, der früh- und mittelhochdeutschen höfischen Lyrik und der einprägsamen Liedgattung der mittel- und süddeutschen Meistersängertradition. ${ }^{24}$ Ihnen sind selbstständigen Zentren der mittelalterlichen epischen Tradition der Russen und Ukrainer, neben der dinarischen Epik, zur Seite zu stellen.

Die parallele Entwicklung der Mehrstimmigkeit spielte sich in West- und Südeuropa ab, in den Ordens-, Kloster- und Stadtzentren Nordfrankreichs, Spaniens, in den Niederlanden, den burgundischen, den englischen und den nordwestdeutschen Regionen. Um dann besonders in Italien und von den italienischen Mehrstimmigkeitsstilen beeinflußt auch in Mitteleuropa weiterzuwirken. Hierher kam die Mehrstimmigkeit erst im 14. Jahrhundert zum Tragen, erreichte aber in den weiteren Jahrhunderten als selbständige Gattung ihre volle Blüte, gleichwertig zu anderen Regionen Europas. Für die weitere Entwicklung des geistlichen Liedes war mit den vielen Reformbewegungen des späten 14., des 15. und 16. Jahrhunderts in Mitteleuropa besonders Tschechien, Böhmen, Südostdeutschland, zusammen mit anderen mitteleuropäischen Ländern ein wichtiger Ursprungsraum, wo Neues entstand und geschaffen wurde. Die Mehrstimmigkeit beeinträchtigte die Singtradition sowohl im geistlichen als auch weltlichen Bereich ganz entscheidend, die Volksmusik mit eingeschlossen. ${ }^{25}$

Das Zentrum für die weitere Entwicklung der Mehrstimmigkeit war Italien, ebenso wie für die Entstehung einer eigenständigen Instrumentalmusik und der Gattung des Musikdramas. Werke italienischer Komponisten und Interpreten haben die europäische Entwicklung über das ganze 16.-18. Jahrhundert weitgehend beherrscht. Ergänzt durch eigene lokale- und Regionalentwicklungen, mit Komponistenpersönlichkeiten, die diesen italienischen Stilfacetten folgten oder sie den eigenständigen soziokulturellen Anforderungen anpaßten. Sie fanden in anderen europäischen Ländern stilistische Nachfolger.

Die räumlich-musikalischen Veränderungen spielten sich allmählich im Laufe der zweiten Hälfte des 18. Jahrhunderts ab, nach einer langen Periode von Unruhen

${ }^{23}$ Zoltán Falvy, Mediterranean Culture and Troubadour Music, Akadémia Kiadó Budapest 1986.

${ }^{24}$ F. P. Knapp, Die Literatur des Früh- und Hochmittelalters in den Bistümern Passau, Salzburg, Brixen und Trient von den Anfängen bis zum Jahre 1273, Graz 1994.

${ }^{25}$ Alica Elscheková, Vergleichende typologische Analysen der vokalen Mehrstimmigkeit in den Karpaten und auf dem Balkan, in: Stratigraphische Probleme der Volksmusik in den Karpaten und auf dem Balkan (O.Elschek, Hg.), VEDA Bratislava 1981, 159-256; Dieselbe, Kultürna geografia tradičných foriem viachlasu so zrete>om na typy rozšírené na Slovensku (Kulturgeographie der traditionellen Formen der Mehrstimmigkeit aus der Sicht der in der Slowakei verbreiteten Typen), in: Ethno-Musicologicum 1/1, 1993, 41-74; Dieselbe, Mehrstimmige traditionelle Singformen im Mittelmeerraum, in: Musicologica Austriaca (A. Schmidthofer, Hg., im Druck). 
religiöser, sozialer, ethnischer und künstlerischer Art. In dieser Zeit fanden in Mitteleuropa, in Süddeutschland, in Österreich, Tschechien, Böhmen, in der Slowakei und anderen Ländern Zentraleuropas entscheidende Stilveränderungen statt. Sie durchbrachen die barocken geistlichen Musikgattungen, und begründeten die neuen stilistischen Mittel der klassizistischen Instrumental-, Tanz-, Kammer- und symphonischen Musik. Sie trugen durch die veränderten sozialen, funktionellen und ethnischen Merkmale maßgeblich zur Neugestaltung der mitteleuropäischen Musik bei. Das musikalische Gesamtbild Europas erhielt neue Impulse. Es waren die ethnisch geprägten volksmusikalischen Musikstile, die in die klassische Musikentwicklung aufgenommen und aufgesogen wurden. Vor allem formten sich neue Typen von metrisch-rhythmischen und vereinfachten harmonischen Strukturen, verbunden mit Tänzen, kennzeichnend für den mitteleuropäischen Bewegungsstil und Bewegungsablauf. Es waren neben den älteren höfischen multiethnischen Tänzen und den ihnen entsprechenden volksmusikalkische Formen, z.B. die Typen der Hajduken- und Faschingstänzen, ${ }^{26}$ die Mazurka, Menuette, später die Polkas u.v.a. Sie leiteten gesamteuropäische und nationale musikalische Umschichtungsprozesse und Veränderungen ein, die die Musik des 18. und 19. Jahrhunderts entscheiden geprägt haben.

Das 19. Jahrhundert verließ diese regional zentrierten europäischen Kulturräume der Musik und verstärkte ein spezifisches, innerlich differenziertes Gesamtbild der europäischen Musikkultur. Vor allem durch ihre nationalen, in der Volksmusik verankerten Musikstile. Sie differenzierte sich durch die angewandten spezifischen tonalen, melodischen, metrisch-rhythmischen u.a. musikalischen Mittel, die sie aber auf eine universellere, gemeinsame romantische, gefühlsbetonte, technisch-stilistische Kompositionsgrundlage stellte. Die Entwicklung strebte, obwohl durch die Anwendung differenzierter Nationalsprachen geprägt (in Wort und Musik), zugleich nach einer universelleren romantischen Musiksprache. Diese annähernd ähnliche Entwicklung blieb bis in das 20. Jahrhundert erhalten. Sie wurde aber immer stärker durch die sich spezifizierenden modernen National-, Regional- und Persönlichkeitsstile umgestaltet und durchbrochen.

Das 20. Jahrhundert verließ weitgehend diese gemeinsame, aber dennoch innerlich differenzierte stilistische Entwicklung und legte immer größeren Wert auf individuelle, lokale, schulische, integrative Prozesse, die sich in der Nachkriegsentwicklung des vorigen Jahrhunderts kristalisierten. Die Einzelpersönlichkeiten, die die Musik der ersten Hälfte des 20. Jahrhunderts mit ihren Persönlichkeitsstilen bestimmten, wurden durch schulische Herausforderungen ersetzt (z.B. mit Darmstadt, Donaueschingen usw. $)^{27}$, wobei sich erstaunlicherweise neue "nationale" Schulen im Rahmen der Neuen Musik z.B. in Polen und auch in anderen Ländern bildeten, verbunden mit eigenständigen Festivals neuer Musik. ${ }^{28}$ Sie etablierten sich in dieser ange-

${ }^{26}$ Oskár Elschek, Hajdukentänze in Geschichte und Gegenwart, in: Historische Volksmusikforschung PWN Kraków 1979, 45-71.

${ }^{27}$ Karl-Heinz Stockhausen, Texte zur Musik, Bd. IV. 1970-1977. DuMont Köln 1978.

${ }^{28}$ Z.B. der Warschauer Herbst, das Zagreber Bienale, Musik Modern in Graz, weitere als Melos-Ethos, und die jährlichen Übersichten des neuen Musikschaffens in Bratislava u.v.a., als Spezialveranstaltungen zu den Gattungen neuer Musik. 
passten und spezifischen Weise der mitteleuropäischen Musiktradition. Dementsprechend spielte sich Universales und Raum- oder ethnisch Spezifisches in der neuen Musikentwicklung in diesen Sonderformen ab. ${ }^{29}$ Ihre Geltung war aber zweifelsohne durch die Begrenzung der modernen Musik im Musikleben abgeschwächt. Deshalb verwirklichte sich der vermeintlich universelle Charakter der modernen Musik nur in einem kleinen Kreis von Musikrezipienten. Ihr universeller Gegenspieler war die kommerzielle Unterhaltungsmusik, die Popularmusik, mit ihren vielen Verästelungen von Stilen und Gattungen, an die sich von den 60er Jahren an die Revivalbewegung anschloß. In dieser erlangte spezifisch Ethnisches, Nationales und Regionales eine immer bedeutendere Stellung. Sie bestimmte die Musikkultur des späten 20. und des beginnenden 21. Jahrhunderts. Sie wurde immer stärker von Phänomenen bestimmt, die wir mit dem innerlich heterogenen Begriff der sog. World Music kennzeichnen.

Europa und die globale Musikentwicklung mit den neuen -Ismen, den modischen Kurzzeitströmungen, den immensen Anstieg der Medien und Kommerzmusik, sind nicht nur Facetten der europäischen, sondern auch der sog. Weltmusik. ${ }^{30}$ Die europäische Sonderentwicklung, entsprechend ihrer geschichtlichen Tradition, aus der Sicht ihrer Kontinuität und Diskontinuität zu untersuchen, zu werten und in die Gesamtentwicklung der Gegenwartsmusik und Musikkultur einzuordnen ist ein schwieriges Unterfangen, das heute über ihre Aufzählung und statistische Erfassung kaum hinausgekommen ist, abgesehen von Einzelanalysen und Stilkennzeichnungen. Sie reflektiert die außerordentlich komplizierte Entwicklung der Gegenwart, wo es besonders schwer ist, spezifische Raumstile- und das ethnisch spezifische Musikgefüge zu erfassen und festzulegen - vor allem auch durch die massive Vermischung von alten und Gegenwartsmusikstilen. Und das in allen Musikgattungen. Das bezieht sich auch auf Mitteleuropa, das entgegen vielen Gemeinsamkeiten, denen sie seitens des Einflusses der globalen Musikentwicklung ausgesetzt war, ihre eigenen Rezeptions- und Schaffensströme besitzt, die viel differenzierter sind als sie es in der Vergangenheit waren.

\section{Gattungen, Stile und geographische Musikdialekte}

Wie spielt sich die Entwicklung im mitteleuropäischen Raum ab? Ist sie eine Reflexion und Rezeption der gesamteuropäischen Entwicklung? Jeder Musikraum hat seine Präferenzen, die mit mentalen, kulturellen Traditionen und geschichtlichen Prozessen zusammenhängen. Diese bestimmen die Auswahl der dominierenden Musikgattungen, die Bevorzugung bestimmter musikalischer Aussagemodelle und die soziale Zuordnung der Musik. Aus dieser Sicht ist Mitteleuropa eine der spezifischen europäischen Regionen, die in Gattungsauswahl, Stilpräferenzen, Werk- und Persönlichkeitsgeschichte der führenden Komponisten eine eigene Strukturgeschichte

\footnotetext{
${ }^{29}$ Dies zeigte der Überblick über die Schulen der europäischen modernen Musik des 20. Jahrhunderts bei Ulrich Dibelius, Modern Musik 1945-1965. Voraussetzungen, Verlauf, Material, R.Piper \& Co Verlag München 1966, derselbe, Moderne Musik II. 1965-1988, München Mainz 1988.

${ }^{30}$ Max-Peter Baumann (Hg.), World Music - Musics of the World, Florian Noetzel Heinrichshoven 1992; Simon Mundi, Music and Globalisation, International Music Council UNESCO Paris 2001.
} 
besitzt. Diese hat sich in jeder Epoche verändert. In manchen Zeiträumen war sie auf besondere innere Kontinuitäten bedacht. In anderen temporalen Zusammenhängen hat sie sich den gesamteuropäischen und geltenden modischen Strömen mehr oder weniger untergeordnet und angepaßt. Die wichtigen Gattungen waren die Gregorianik und die neugestalteten Hymnen, Sequenzen zwischen dem 9.-13. Jahrhundert, außer des europäischen Repertoires auf lokale und regionale Heilige bezogen, mit manchen ethnischen Reflexionen in der Behandlung der Texte und Weisen (Tonalität, Motivik, Melismatik). Die Mehrstimmigkeit fand hier einen besonders fruchtbaren Boden, wobei Polen, Tschechien und die Slowakei in der Mehrchörigkeit spezifische mitteleuropäische Stilfacetten entfalteten. Mitteleuropa war für das geistliche Lied und sein gesamtes Liedrepertoires ein besonders fruchtbarer Boden. Seine Ausstrahlung ging weit in andere europäische Regionen mit den sich verändernden konfessionellen Bewegungen. Vor allem die Reformation und das Aufgreifen des Wiclifianismus im Husitismus, erhob die Musik und die geistlichen Volks- und volkstümlichen Gesänge zu den mächtigsten sozialen und sozialisierenden Mitteln ihrer Zeit. Nachfolgende Reaktionen der Gegenreformation schöpften aus diesen geistlichen und musikalischen Widersprüchen und trugen zur gedanklichen und stilistischen Umgestaltung der Barockmusik bei, wie sie sich letztlich in Italien etablierte. Mitteleuropa war für die folgende klassizistische Musik der richtige Schmelztiegel, der sowohl italienisches, böhmisches, nord- und süddeutsches, französisches und englisches (vor allem aus den ästhetisch sensitiven Theorien der englischen Kunsttheoretiker), ebenso wie Völkisches aus dem mittel- und ostmitteleuropäischen Raum verarbeitete Als Beispiel dieser stilitstischen Überschneidungen kann die Musik Joseph Haydns dienen. Auch fand in diesem östlichen Grenzraum bei Wien der Umschwung zwischen der klassizistischen und romantischen Musik durch ihre typischen Vertreter wie Franz Schubert ebenso wie Johannes Brahms und Franz Liszt ihre richtiggehenden Vertreter, vor allem was das Klavierschaffen betrifft, nicht zu sprechen vom Lied. Auch der südostdeutsche Robert Schumann gehört zu dieser mitteleuropäischen Entwicklungslinie, ebenso mit seinen mitteleuropäischen Wurzeln Frederic Chopin, obwohl er sein ganzes Leben in Frankreich verbrachte. Auch wenn ich hier nur einige Namen aus dem Zentralbereich Europas erwähnte, war ihre großregionale Musikausstrahlung und ihre Resonanz mit Hunderten von Komponisten und Tausenden von Werken in Mitteleuropa unvergleichlich größer. Ich möchte hier nicht die mitteleuropäischen nationalen Musikschulen aufzählen, ebenso wie die Bedeutung Zentraleuropas für die Neuromantik und das fortgesetzte symphonische Schaffen. Auch mich nicht mit den Details, der in Wien zentrierten, sog. I. Wiener Schule auseinandersetzen, mit ihrer immensen Bedeutung für die Musik der zweiten Hälfte des 20. Jahrhunderts usw. Jeder einzelne Aspekt verdient in seiner Signifikanz behandelt zu werden. Dabei muß viel differenzierter an die einzelnen mitteleuropäischen Länder herangegangen werden, weil sie außer den erwähnten europäischen und mehr oder weniger mitteleuropäischen Gesamttrend, ihre eigene Entwicklung in den einzelnen Ländern Mitteleuropas, im Kontext aber auch getrennt, verwirklichen. Das ist der Inhalt dieser unterschiedlichen Schichten der Musikgeschichtsforschung Mitteleuropas, die diese innere ethnische, nationale, regionale und lokale Differenzierung auch im Bezug zu ihren Gattungen und Funktionsbereichen erfassen muß. 
Hier soll noch ein besonderer Aspekt zur Sprache gebracht werden. Beziehungsmodelle, die im jeweiligen Raum zwischen der Kunst-, der Popular- und der Volksmusik bestehen. Nicht nur was das vorhergehende und gegenwärtige Jahrhundert betrifft. Wie integriert oder desintegriert stehen sie zueinander? Wie groß ist ihre gegenseitige Akzeptanz oder Mißachtung? Hier ist der mitteleuropäische Raum weitgehend gespalten: in einen zentralen, einen westlichen, einen nördlichen, östlichen und südöstlichen. Das hängt mit dem Stellenwert der jeweiligen Volksmusik als real existierender Gattung im Musikgefüge zusammen, und mit dem Umstand, wie diese Tradition erhalten, gepflegt oder zurückgedrängt wurde. Wie sie im traditionellen Musikbewußtsein vertreten ist oder künstlich kommerziell revitalisiert oder nationalvolkstümlich ausgeschlachtet wird. In welchem Zeitraum und mit welcher Intensität ist dies geschehen? Hat sich eine Art volkstümlicher Musik entwickelt? In welcher Beziehung zur ländlichen Musik? Dasselbe bezieht sich auf die Popularmusik insgesamt. Nicht nur im heutigen Sinne, sondern auch auf die Popularmusik etwa im 18. oder 19. Jahrhundert, erweitert auf die Unterhaltungs-, Tanz- oder die volkstümliche Musik, wie sie in einem bestimmten Zeit- und Raumgefüge integriert war. Dem nachzugehen und diese Prozesse zu untersuchen, ist eine eher wenig oder ungenügend wahrgenommene Facette der Musikgeschichtsforschung. Die mitteleuropäische mit einbezogen. Selbstverständlich mit großen unterschieden in den einzelnen mitteleuropäischen Ländern. Es ist ein generelles, nicht nur ein einfaches, auf die Musikdetails bezogenes vergleichende Verfahren, an dem es mangelt. Es ist vor allem eine soziokulturelle und funktionsbezogene Frage, die es zu bestimmen gilt, um die gegenseitige Wirkung und Auswirkung zwischen den einzelnen Musikschichten festzuhalten. Die soziale Schichtung der Musik und die an sie gebundene stilistische, ist zweifelsohne so alt wie die Musik. Die sozialen Musikschichten sind aber durchlässig, ihre Gattungen, Formen und stilistischen Mittel stehen in einem permanenten Dialog. So wie die Sozialstruktur einer Gesellschaft nur relativ abgegrenzt ist, eine aufeinander bezogene Einheit bildet, so ist es auch mit der Musikkultur, die einen Gesamtorganismus bildet. Dem wird in der Musikforschung und in der Musikgeschichtsforschung kaum Rechnung getragen. Die einzelnen Musikschichten und Phänomene werden überwiegend getrennt und beziehungslos nebeneinandergestellt. Nicht aber bei den Menschen der Zeit. Sie Leben und erleben das Gesamtgefüge ihrer Musikkultur stärker ausgeprägt. Ein Komponist perzipiert diese Unterschiede viel sensibler und reagiert in seinem Schaffen auf diese unterschiedlichen Schichten bewußt oder unbewußt. Der Forschung stellt sich die anspruchsvolle Aufgabe diese Prozesse im konkreten Musikschaffen aufzudecken. Denn nur durch sie kann sie die Bedeutung der einzelnen Musikgattungen und Werke, als auch den Gesamtkontext einer Musikkultur erkenntlich machen. ${ }^{31}$ Alle bilden einen Teil des Musikbewußtseins ihrer Zeit, der Gemeinschaft, als auch jedes einzelnen ihrer Mitglieder.

${ }^{31}$ Hier stellt sich auch die Frage inwiefern können genetische und historische Entwicklungen in der Volksmusik festgehalten werden. So wie diese Frage z.B. in der slowakischen Volksmusikforschung gehandhabt wurde, mit allen ihren hypothetischen Gedankengängen. Siehe Oskár Elschek, Genetické teórie >udovej hudby a Kresánková klasifikácia (Entwicklungstheorien der slowakischen Volksmusik und die Klassifikation des slowakischen Volksliedes von Jozef Kresánek), in: Ethno-Musicologicum I, Bratislava 1993, 11-25. 
MUZIKOLOŠKI ZBORNIK • MUSICOLOGICAL ANNUAL XL

Diese Probleme sind nicht nur Teil der Erforschung jeder Musikkultur, sondern auch eines komplexen Kulturraumes so wie es der mitteleuropäische ist, insbesondere mit seiner vielschichtigen Heterogenität. Auch wenn Musik immer etwas quasi Universelles in sich birgt, wahrscheinlich mehr als die Gattung der bildenden Kunst, und vor allem die Literatur, die sich durch die national sprachlichen Barrieren vom 17. Jahrhundert immer stärker differenzierte. Hinzutreten immerhin auch die Beziehungen zwischen den einzelnen Kunstgattungen, die aus dieser Sicht des Universellen, des Regionalen und Raumübergreifenden sehr unterschiedlich strukturiert sein können.

Wenn wir von Musikdialekten sprechen, ist es ein gesamt von charakteristischen Merkmalen, die sich auf die einzelnen Musikparameter beziehen, metrorhythmischer, tonaler, melodischer, formbestimmender etc. Art. Sie sind Teil sowohl der Persönlichkeitsstile von Komponisten als auch allgemein selektiver musiktechnischer Tendenzen, die sich in der Werk- und Gattungsauswahl manifestieren.

Diese Probleme allgemeiner Art begleiten unser Verständnis der europäischen Musikkultur, die zweifelsohne ihre eigene Relevanz auch aus der Sicht der Musikkultur Mitteleuropas haben.

\section{Musikgeschichten Gesamt- und Mitteleuropas - ihre Entwicklung und Beziehungen}

Mitteleuropa ist ein spezifisches Abbild Europas in einem begrenzten Raum. Alles was sich in der Musikgeschichte Europas abgespielt hat, fand seine angepaßte Entsprechung, Reflexion und Reaktion auch in der mitteleuropäischen Musikentwicklung. In manchen Regionen stärker reflektierend in anderen variabel gehandhabt. Hier muß von vorne herein auf einige Gemeinsamkeiten dieser Mikroräume hingewiesen werden. Der mittelwestliche Raum mit Österreich (auch mit seinen Unterregionen), weiter mit Bayern, der Westschweiz, hat nicht nur seine sprachlichen Gemeinsamkeiten, sondern auch sich überschneidende, gemeinsame mikroregionale Musikentwicklungen und Stilbereiche. Südostdeutschland (z.B. Sachsen, Thüringen u.a.), ebenso wie Schlesien, Tschechien und die böhmischen Grenzländer waren miteinander nicht nur konfessionell, sondern auch durch die protestantische Kirchenmusik und Musiktradition im weiteren Sinne des Wortes verknüpft. Der Osten Österreichs, die Slowakei, Teile West- und des heutigen nördlichen Ungarns (der Republik Ungarn - nicht im Sinne Ungarns, eines noch immer verwendeten antiquierten historischen Begriff, der keine kulturelle und staatspolitische Gegenwart respektiert), unterlagen ähnlichen Determinationen musikhistorischer Art. Dies bezieht sich z.B. auf die südlichen Teile Österreichs (mit Kärnten, der Steiermark) und Slowenien. Die migrierenden Komponisten waren z.B. Jacobus Gallus, Samuel Capricornus, Juraj Družecky, Gaudentius Dettelbach, aber auch Franz Liszt und Ján Levoslav Bella, ebenso Béla Bartók - um nur einige Namen zu nennen. Es waren in der Regel Musiker und ihre Werküberlieferung, verbunden durch eine ähnliche musikalische Haltung und Gattungsauswahl. Entsprechend der Zeit, des aktuellen kulturellen Raumes in dem sie wirkten, mitbestimmt durch ihre spezifischen persönlichen stilistischen Präferenzen. Es war der sozial bedingte Lebens- und Kulturraum, der ihre Aktivität bestimmte. 
Die erwähnten Beziehungen aber generell gelten zu lassen, wäre unzutreffend. Die inneren kulturgeographischen, musikalischen Beziehungen änderten sich in jeder Epoche und geschichtlichen Periode. Dies geschah im Zusammenhang mit den sich verändernden Einflußzonen und kulturhistorischen Prozessen Mitteleuropas. Es war der Kontext des Kulturraumes, die Beziehungen zu den ihnen nahe stehenden Kulturen, die einen stabilisierenden Einfluß ausübten. Es gilt von Fall zu Fall diesen festzustellen, um ihre individuellen Auswirkungen kennzeichnen zu können. Das ist der Grund, weshalb wir keine mitteleuropäische Musikgeschichte haben, weshalb solche Versuche nur vereinzelt vorliegen. Auf das Mittelalter bezogen wurden diese früh von Franz Zagiba unternommen, mit seiner Reihe: Forschungen zur älteren Musikgeschichte, mit seiner einleitenden Monographie Musikgeschichte Mitteleuropas $I^{32} \mathrm{Um}$ diesen Raum in seiner spezifischen Ausprägung zu kennzeichnen schreibt Zagiba: "Im Unterschied von Westeuropa hat die Musikentwicklung Mitteleuropas auf verschiedenen Gebieten Bodenständiges aufzuweisen, so etwa im frühzeitlichen Musikinstrumentarium oder in der Praxis des gregorianischen Gesanges im Frühmittelalter, der im Rahmen der Missionen aus Italien, Irland oder Byzanz hier seinen musikalisch-liturgischen Niederschlag fand."( S. 9). Diese frühmittelalterliche Tradition im südlicheren Raum Mitteleuropas, in Slowenien, untersuchen aus quellenerschließender Sicht Beiträge in thematischen Sammelbänden. ${ }^{33}$ Die Ausgabe zum 60. Geburtstag Theophil Antoniceks hat einen enger gefaßten Titel: Österreichische Musik. Musik in Österreich. Beiträge zur Musikgeschichte Mitteleuropas, ${ }^{34}$ und konzentriert sich ebenfalls auf Spezialstudien. Sie hatten überwiegend einen regionalübergreifenden Charakter aber keine Ambitionen eine systematische überblicksartige Zusammenfassung vorzulegen. Dies ist nur ausnahmsweise versucht worden. ${ }^{35}$ Die Veranstaltung von Konferenzserien, Symposien in internationaler Besetzung, besucht von Forschern aus den Ländern Mitteleuropas, waren in den 90er Jahren der gangbarste Weg, um mitteleuropäische Kultur- und Musikvergleiche durchzuführen. $\mathrm{Zu}$ ihnen gehört eine weitere Serie von veröffentlichten Sammelbänden - Historia Musicae Europae Centralis, die in Bratislava erschien. Sie wurden Anfang der 90er Jahre von Pavol Polák $(1994,1997)$ initiiert. ${ }^{36}$ Vorerst waren die Tagungen den dominierenden instrumentalen und vokalen Stilentwicklungen der klassizistischen und barocken Musik in Mitteleuropa gewidmet. Wie sich im Lauf der Jahre die Interpretation der mitteleuropäischen und nationalen Musikgeschichten veränderte, ist aus den Worten von Gernot Gruber ersichtlich: "In den 1970er Jahren, bei unseren Über-

${ }^{32}$ Musikgeschichte Mitteleuropas von den Anfängen bis zum Ende des 10. Jahrhunderts, Verband der wissenschaftlichen Gesellschaften Österreichs Wien 1976. Hier wird der zentrale Teil Mitteleuropas behandelt, der Grenzbereich zwischen Österreich und den slawischen Völkern, insbesondere den Slowaken.

${ }^{33}$ Medieval Music in Slovenia and its European Connections, Jurij Snoj (Hg.), Proceedings from the international symposium, Ljubljana, June $19^{\text {th }}$ and $20^{\text {th }} 1997$, Scientific Research Centre SASA, ZRC Publishing Ljubljana 1998.

${ }^{34}$ Elisabeth Theresia Hilscher (Hg.). Verlegt bei Hans Schneider Tutzing 1998.

${ }^{35}$ Oskár Elschek, Musikgeschichtliche Prozesse im mitteleuropäischen Raum und ihre musikwissenschaftliche Reflexion, in: Österreichische Musik u.w. E. Hilscher (Hg.). Tutzing 1998, 11-27.

${ }^{36}$ Pavol Polák (Hg.), Musik Mitteleuropas in der 2. Hälfte des 18. Jahrhunderts, Institut für Musikwissenschaft der Slowakischen Akademie der Wissenschaften, ASCO Art \& Science Bratislava 1993 (Historiae Musicae Europae Centralis 1); derselbe, Mittleuropäische Kontexte der Barockmusik, Academic Electronic Press Bratislava 1997 (Historia Musicae Europae Centralis 2). 
legung zur ersten Auflage der Musikgeschichte Österreichs haben wir uns zu einer strengen Begrenzung unseres Darstellungsraumes auf das Gebiet der heutigen Republik entschlossen. Dies geschah zum einen aus Gründen der Pragmatik, um eine beherrschbare Materialfülle zu erhalten, und ließ sich auch mit dem Hinweis darauf, daß das heutige Österreich in etwa den Kernländern der Habsburger entspricht, historisch einigermaßen legitimieren. Zum anderen scheuten wir uns, historische Kulturbeziehungen über die heutigen politischen Grenzen hinweg eingehender zu erörtern, um nicht den Verdacht einer kulturellen Vereinnahmung ehemals habsburgisch beherrschter Länder zu erregen. Jeglicher, und sei es auch bloß ein in ferne Geschichte projizierter Hegemonismus ist uns auch heute fremd-dennoch stehen wir vor einer gewandelten Situation, die uns und unsere Kollegen aus anderen Ländern unverkrampfter agieren und auch Gemeinsamkeiten in angemessener Weise aussprechen läßt." ${ }^{37}$ In den folgenden Jahrzehnten erfüllten sich diese Vorstellungen, auch wenn die Schwierigkeiten bei der Erfassung mitteleuropäischer und der Landesgeschichten der Musik, nicht geringer wurden. Die Zusammenarbeit hat zugenommen und der Dialog bei der Klärung quellenkundlicher und stilistischer Fragen wurde zutreffender und detaillierter. Ende der 90er Jahre folgte der Konferenzserie von Pavol Polák, auf die klassizistische und barocke Vokal- und Instrumentalmusik Mitteleuropas ausgerichtet, eine weitere Tagungsserie. Sie wurde von Ladislav Kačic veranstaltet, diesmal unter der Schirmherrschaft des Kabinets für Slawistik der Slowakischen Akademie der Wissenschaften. Es war ein Trio von internationalen Konferenzen und Veröffentlichungen, die vorrangig der geistlichen Musik gewidmet waren. Sie standen im Bezug zu den geistlichen Orden und ihrer musikalische Bedeutung. Es war die Musik der Gegenreformation und die Behandlung eines wichtigen Gesangsbuchs, des Cantus Catholici, mit einer reichen Bezugsstruktur zur Musik der mitteleuropäischen Länder, die als Tagungsthemen gewählt wurde. Die von Ladislav Kačic übernommenen Tagungen, die die geistlichen Musikgattungen analysierten, waren viel stärker auf die früheren Entwicklungen des 16. und 17. Jahrhunderts ausgerichtet. ${ }^{38}$ Auf die besondere Situation der Erforschung des Kirchenliedes nimmt das Vorwort des Herausgebers (Zum Geleit) bezug, wenn er meint: "Das Kirchenlied ist nicht nur ein typisch internationales Forschungsobjekt (mit vielen Konsequenzen) sondern auch eine Erscheinung, die bekannterweise 'keine Grenzen kennt', eine Erscheinung, die im wahrsten Sinne des Wortes 'international' (trotz der verschiedenen Sprachen) ist. Die Problematik des slowakischen Kirchenliedes des 17. Jahrhunderts ist jener des tschechischen, österreichischen, ungarischen und polnischen sehr verwandt; auch diese Konferenz zeigte, daß viele gemeinsame Probleme 'auf dem Tisch' liegen. Eine neue Sparte stellt das 'sich Öffnen' zum Osten, zum paraliturgischen Lied des byzantinischen Ritus vor, nicht nur in der Slowakei,

${ }^{37}$ Gernot Gruber, Konzeptionelle Schwierigkeiten der Musikgeschichtsschreibung im mitteleuropäischen Raum, in: P. Polák (Hg.), Musik Mitteleuropas in der 2. Hälfte des 18. Jahrhunderts. ASCO Bratislava 1994, S. 21-22.

${ }^{38}$ Ladislav Kačic (Hg.), Musik der geistlichen Orden in Mitteleuropa zwischen Tridentismus und Josephinismus, Academic Electronic Press Bratislava 1997; derselbe, Gegenreformation und Barock in Mitteleuropa, in der Slowakei, Academic Electronic Press Bratislava 2000; derselbe, Cantus Catholici a duchovná pieseH 17. storočia v strednej Európe (Cantus Catholici und das Kirchenlied des 17. Jahrhunderts in Mitteuropa), Slawistisches Kabinet SAW. Bratislava 2002. 
sondern auch in der Ukraine. Es zeigt sich schon heute (ein wenig paradox), daß in der Vergangenheit Westen und Osten in der Musik mehr als heute verbunden waren." ${ }^{39}$

Jede Musikgattung hat unterschiedliche nationale und internationale Facetten, auch ein solches Phänomen wie die Volksmusik. Sie wird viel stärker als traditioneller Träger von ethnischen Stileigenschaften verstanden. Aus dieser Sicht war die mitteleuropäische Volksmusikforschung und Ethnomusikologie über eine lange Zeit in internationale komparative Projekte eingebunden. Es war die Volksmusik der Karpaten und des Balkans, aber auch neuere stilistische Entwicklungen, die untersucht wurden..$^{40}$ Die Volksmusikforschung war von ihren Anfängen an auf internationalen vergleichenden Methoden und Strategien aufgebaut, wie das die Gründung spezialisierter Studiengruppen im Rahmen des International Council for Traditional Music in der UNESCO dokumentieren. Sie wurden überwiegend von Forschern aus Mitteleuropa geleitet und auch thematisch bestimmt. ${ }^{41}$

In der erwähnten Serie von länder- und raumübergreifenden Untersuchungen ist noch auf eine weitere thematische Facette zu verweisen, auf jene die der slawischen Musik gewidmet war. Es ist nicht von ungefähr, daß gerade die drei letzten erwähnten Bände von L. Kačic im Slawistischen Kabinet der Slowakischen Akademie herausgegeben wurden. Es ist aber auch die vor zwei Jahrzehnten veranstaltete Tagung Music of the Slavic nations and its influence upon European musical culture, die auf Musikbeziehungen und Besonderheiten der Kontakte und Entwicklungen zwischen den slawischen Ländern und Nationen verwies. In diesem slawischen Bezug ist noch auf die ältere Tagung zu verweisen, die sich vor allem auf die altslawische liturgische Musik und die Volksmusik konzentrierte. ${ }^{42}$ Es war die Zeit in welcher versucht wurde eine Slawistische Musikwissenschaft zu begründen, wie sie Igor Belza vorschwebte, mit seinen Monographien der polnischen und tschechischen Musik gewidmet. Auch regionale und nationale Teilbereiche der slawischen Musikkulturen wurden untersucht, ${ }^{43}$ wie das bei der Publikation von Dragotin Cvetko getan wurde, in seiner Musikgeschichte der Südslawen, welche mittel- und südslawischen Beziehungen in den europäischen Kontext einfügte. ${ }^{44}$ Länder- oder nationale Musikkultu-

${ }^{39}$ L. Kačic (Hg.), Cantus Catholici a duchovná pieseH 17. storočia v strednej Európe (Cantus Catholici und das Kirchenlied des 17. Jahrhunderts in Mitteleuropa), Slawistisches Kabinet SAW. Bratislava 2002, S. 9.

${ }^{40}$ Oskár Elschek (Hg.), Stredoeurópske štýly tradičnej hudby a tanca (Middle European Stiles in Traditional Folk Music and Dance). ASCO art \& science Bratislava 2002.

${ }^{41}$ Es war z.B. die Studiengruppe für Analyse und Klassifikation, die Studiengruppe für die Herausgabe der historischen Quellen der Volksmusik, die Studiengruppe für Volksmusikinstrumente u.a., wie das aus ihren Berichten ersichtlich ist: Andreas Michel, Publications and Activities of the ICTM Study Group on Folk Musical Instruments, in: Yearbook of the ICTM 23, 1991, 172-180; Oskár Elschek, Publications and Activities of the ICTM Study Group on Analysis and Systematization, dtto, 181-188; Wolfgang Suppan, Publications and Activities of the ICTM Study Group on Historical Sources of Folk Music 1967-1988, dtto. 189-194.

${ }^{42}$ Ladislav Mokrý (Hg.), Anfänge der slawischen Musik, Verlag der Slowakischen Akademie der Wissenschaften Bratislava 1966.

${ }^{43}$ In dieser Beziehung muß erwähnt werden, daß ich auf die umfangreiche Literatur der polnischer und tschechischer Musikgeschichtsforschung nur sehr beschränkt verwies, um den Rahmen dieses Beitrages nicht weitgehend sprengen würde

${ }^{44}$ Musikgeschichte der Südslawen, Bärenreiter Kassel u.a. Založba Obzorja Maribor 1975. 
ren übergreifende Aspekte waren in der Regel auch in den tschechoslowakischen musikgeschichtlichen Synthesen enthalten, vor allem in heimatkundlichen Enzyklopädien und Synthesen. ${ }^{45}$ Dies ist in vielen mitteleuropäischen Läṇdern geschehen, abgesehen von den selbständigen synthetischen Werken, auf die ich in anderen Veröffentlichungen hingewiesen habe. ${ }^{46}$

Auch wenn zahlreiche internationale musikwissenschaftliche Aktivitäten in Mitteleuropa sich mit einem breiteren kulturgeographischen Themenkreis beschäftigen, die aus der internationalisierten Musikentwicklung resultieren, so ist doch die üblichere, aber auch qualitativ organischere Art, die Musikgeschichtsschreibung, wie sie im nationalen oder Länderrahmen verwirklicht wird, darzustellen. Sie schließen keine länderübergreifende Entwicklung und Phänomene aus, sondern interpretieren sich meist gemäß ihrer geographischen und ethnisch-kulturellen Besonderheiten. Es kann nicht meine Aufgabe sein, den Anteil der weiter gefaßten europäischen und mitteleuropäischen Beziehungen in solchen nationalen Musikgeschichten zu werten. ${ }^{47}$ Es ist aber augenscheinlich, daß ihr Schwerpunkt in den nationalen oder länderbegrenzenden Umfang liegt. Dies entspricht ja auch ihrer kulturhistorischen und funktionellen Einfügung, in welcher die jeweilige Musik gelebt hat, unabhängig von ihrer Provenienz oder Entstehungsgeschichte. Diese, vor allem in der frühen und älteren Musikgeschichte zu eruieren, sie entsprechend quellenmäßig zu erfassen und einzuordnen, ist häufig besonders schwierig. Und hier beginnen nicht selten die Probleme, denn der Wirkungsort und der Wirkungskontext ist ein unterschiedlicher, im Vergleich zu jenem, wo sich diese musikgeschichtlichen Quellen heute befinden. Diese nicht genügend sensible Ignoranz in der Einordnung und Wertung der Quellen in ihrem Wirkungs- und Entstehungsland ist ein häufig auftretendes Problem der mitteleuropäischen, aber nicht nur der mitteleuropäischen Musikgeschichtsforschung. Das erfordert ein besonders sorgfältiges, korrektes und einsichtiges Verfahren, sich des rein nationalen und nationalistischen Blickwinkels zu entledigen, um die Musik zu begreifen und historisch zu interpretieren. Auch die alten und neuen Grenzziehungen, welche die historischen regionalen Verschiebungen verunsichern, ist an den veröffentlichten Länder-Musikgeschichten kaum ablesbar, sie wurden meist ignoriert oder verschwiegen. Wird das Konzept der mitteleuropäischen Musikgeschichten nur ein nationales und nur nach Ländern und Regionen begrenzt verstandenes bleiben? Wird die Vielschichtigkeit der jeweiligen kulturgeschichtlichen Einordung der Musik berücksichtigt werden? Davon hängt die Qualität der erreichten Forschungsergebnisse ab.

Die sprachliche Barriere spielt bei den Forschungen eine nicht unerhebliche Rolle, insofern nur solche Veröffentlichungen von der internationalen und länderübergreifenden Musikwissenschaft gelesen, verstanden und akzeptiert werden, die in Welt-

${ }^{45}$ Ladislav Mokrý, Slovenská hudba, in: Československá vlastiveda IX, Umní 3 Hudba, Praha 1971; Richard Rybarič, $H u d b a$, in: Slovensko IV, Kultúra I., Bratislava 1979.

${ }^{46}$ Oskár Elschek, Dejiny slovenskej hudby od najstarších čias po súčasnose, ASCO art and science Bratislava 1996 (engl. Ausgabe 2003), und derselbe, Musikgeschichtliche Prozesse im mitteleuropäischen Raum und ihre musikwissenschaftliche Reflexion, in: Österreichische Musik u.w. E. Hilscher (Hg.). Tutzing 1998, 11-27.

${ }^{47}$ Dies ist z.T. geschehen in Oskár Elschek (Hg.), A History of Slovak Music from the Earliest Times to the Present, VEDA Publisher of the Slovak Academy of Sciences Bratislava 2003, im Kapitel: Slovak Music in the Social and Cultural Context of Europe, S. 15-44, insbesondere: The Musical History of "Small" Nations, S. 23ff. 
sprachen erscheinen. Bei 80\% der Veröffentlichungen ist dem aber nicht so. Sie erscheinen in den Landessprachen. Sie bleiben von der internationalen Musikforschung weitgehend unberücksichtigt und unausgewertet und spielen nur in der heimischen Forschung jene Aufgabe die ihnen zusteht. In den einzelnen Ländern Mitteleuropas stehen jeweils an die 5-10 Synthesen (z.T. auch mehrbändige) zur nationalen Musikgeschichte zur Verfügung. Insbesondere in Polen,. Tschechien, der Slowakei usw., die aber in den Landessprachen verfaßt wurden. Außerdem gibt es in den einzelnen Ländern zahlreiche spezielle musikgeschichtliche und musikwissenschaftliche Zeitschriften und Sammelbände, die sich mehr als ein Jahrhundert der Erforschung ihrer Musikkultur in landessprachlichen Veröffentlichungen widmen. Sie wurden und werden von der europäischen Musikforschung wegen ihrer sprachlichen Begrenztheit, und jeweils auch von den "anderen" nicht rezipiert. Mit diesem Zustand kann keine zufriedenstellende internationale Musikforschung verwirklicht werden. Sie kann nicht aus Fragmenten und Auszügen von Forschungsergebnissen bestehen.

\section{Musik als Adaption und Neuschöpfung in Mitteleuropa}

Jeder musikgeschichtliche Ablauf ist eine Summe eigener und übernommener Werküberlieferungen. Und dies ist auch in Mitteleuropa der Fall, wobei hier zumindest eine Viererbeziehung ins Kalkül gezogen werden muß:

1) die Schicht des gesamteuropäischen stilistischen Ablaufs,

2) jene des mitteleuropäischen Repertoires, der jeweiligen Länderentwicklung, also in einem gewissen Sinne die nationalen und multinationalen Entwicklungen in ihrem Gesamtrahmen.

3) $\mathrm{Zu}$ diesen kommt noch der regionale und mikroregionale Rahmen, mit seinen kultursozialen und geschichtlichen Besonderheiten.

4) Stadtgemeinschaften, inneregionale oder überregionale Fürstenhäuser, Familiensitze, Klöster und Orden, Schulen und andere quasi institutionelle Bereiche, prägen künstlerische Individualitäten, und sind weitere Faktoren, welche die Entwicklung beeinträchtigt haben.

Allen diesen stilbildenden Bereichen muß der gebührende Platz in der musikgeschichtlichen Forschung zugewiesen werden. Dies bezieht sich allerdings nicht nur auf die Kunstmusik, sonder gleichermaßen auf die Popular- und Volksmusik. Es ist ein vielschichtiges musikalisches Netzwerk, welches eine Gesamtheit von kulturellen Aspekten in der Musikgeschichte bilden.

Mitteleuropa ist aus dieser Sicht der europäischen Musikgeschichtsforschung ein relativ interressantes, aber ein ebenso kompliziertes Forschungsgebiet. Vor allem im Hinblick auf die am Anfang erwähnte multiethnische Entwicklung, auf die Formung der einzelnen innerregionalen Kontinuitäten, der nationalen Musikkulturen, ebenso wie auf die Vielzahl der länder- und kulturübergreifenden Probleme und ihre sprachlichen Grenzen. Diese sind nur in einer fruchtbaren und sachlichen Zusammenarbeit zwischen den einzelnen Länderforschungen und Institutionen zu überwinden, um außer auf das Mosaik der einzelnen Musikkulturen Mitteleuropas auch auf ihre wesentlichen verbindenden Elemente hinweisen zu können. 